\title{
Modeling spatial variability in the life-cycle costs of low-volume forest roads
}

\section{Journal Article}

\section{Author(s):}

Stückelberger, Jürg Andreas; Heinimann, Hans Rudolf; Burlet, Edouard Charles

Publication date:

2006-10

Permanent link:

https://doi.org/10.3929/ethz-b-000001954

Rights / license:

In Copyright - Non-Commercial Use Permitted

Originally published in:

European Journal of Forest Research 125(4), https://doi.org/10.1007/s10342-006-0123-9 


\section{Modeling spatial variability in the life-cycle costs of low-volume forest roads}

\begin{abstract}
Cost estimation is probably the most decisive factor in the process of computer-aided, preliminary planning for low-volume road networks. However, the cost of construction is normally assumed to be routeindependent for a specific project area, resulting in suboptimal layouts. This is especially true for mountainous terrain and in areas with unstable subsoil. Here, we present a model for more accurately estimating spatial variability in road life-cycle costs, based on terrain surface properties as well as geological properties of the subsoil. This parametric model incorporates four structural components: embankment, retaining structures, pavement, and drainage and stream-crossing structures. It is linked to a geo-database that allows users to derive location-specific parameter values as input. In applying this model, we have demonstrated that variability in costs ranges widely for mountainous areas, with the most expensive construction being approximately five times greater there than on more favorable sites. This variability strongly affects the optimal layout of a road network. First, when location-specific slope gradients are considered, costs are reduced by about $17 \%$ from those calculated via currently available engineering
\end{abstract}

Communicated by Walter Warkotsch

J. A. Stückelberger $(\bowtie)$

Forest Engineering Group,

Swiss Federal Institute of Technology ETH,

8092, Zurich, Switzerland

E-mail: stueckelberger@env.ethz.ch

Tel.: + 41-44-6323242

Fax: + 41-44-6321146

H. R. Heinimann

Forest Engineering Group,

Swiss Federal Institute of Technology ETH,

8092, Zurich, Switzerland

E-mail: heinimann@env.ethz.ch

E. C. Burlet

Forest Engineering Group,

Swiss Federal Institute of Technology ETH,

8092, Zurich, Switzerland

E-mail: burlet@env.ethz.ch practices; when both slope gradient and geotechnical formations are included, those costs are decreased by about $20 \%$. Second, the length of the road network is increased by about $4 \%$ and $10 \%$ respectively, compared with current practices.

Keywords Low-volume forest roads - Route-dependent construction cost - Spatial variability of life-cycle cost . Route location - Optimal road network

\section{Introduction}

Computer-aided engineering approaches for the layout of low-volume forest road networks have been in development since 1970s (Kirby 1973; Mandt 1973; Dykstra 1976), resulting in software packages, such as PLANS (Twito et al. 1987), PLANEX (Epstein et al. 2001), or NETWORK 2001 (Chung and Sessions 2001). Each formulates the problem in terms of combinatorial optimization, which comprises three main components: (1) a finite set of possible road segments for a specific project area, (2) an objective function, and (3) an optimization mechanism. The objective function represents both construction and transportation costs, which must be minimized by considering specific constraints. Accuracy of this cost information is a decisive factor in identifying an optimal or at least near-optimal solution. However, construction-cost estimates very often rely on expert judgments, and are assumed to be route-independent. Because high costs are increasingly becoming a major concern when building low-volume roads, engineers urgently need to develop an effective, more highly accurate procedure for estimating route-dependent costs.

Three methodological streams of cost estimating are available: (1) direct rule-of-thumb estimating, (2) estimating relationships, and (3) bottom-up parametric modeling. The first method employs a judgmental estimate by an expert familiar with the current task. Such direct estimations rely more or less on data from past 
projects or programs, with readily available data. This approach has historically been dominant in preliminary road-network planning, serving as the basis for software packages, such as PLANEX or NETWORK 2001.

The second approach, using estimating relationships and formulae, calculates the cost of either individual components or the entire system, and is based on costdriving technical parameters. Markow and Aw (1983) have identified relationships to predict the volume of earthwork needed, as well as the numbers of culverts and bridges per unit length. Those relationships estimate physical construction quantities, which are then multiplied by respective unit prices and summed to determine the total cost of construction. In contrast, Anderson and Nelson (2004) have devised an estimating relationship that uses only road gradient as an input parameter.

The third method-bottom-up parametric modeling - starts with a work-breakdown structure (WBS) that represents the subsystems, components, or elements of a whole project. Here, similar deliverables are grouped into classes and a physical measure is then used as an indicator for cost within each class. Durston and Ou (1983) have developed an approach that considers the following subsystems: earthwork, clearing area, grubbing area, seeding area, ditch relief culverts, drainage crossings, and the aggregate volume for surfacing. This particular model, run on a hand-held computer, has been demonstrated to be more effective and accurate than previously used techniques. Heinimann (1998) has developed a similar approach that has been proven useful for cost-modeling under steep-slope conditions.

Here, we report the development and analysis of a model for estimating the life-cycle costs of forest roads, using location-specific parameters within a given project area. Our emphasis is on low-volume routes through mountainous regions. In addition, we present validation results, and discuss the influence of different cost-modeling options on both construction cost estimations and road network layouts.

\section{Methods}

Model development

\section{Cost estimation framework}

Understanding how the design elements of road and terrain features can influence life-cycle costs is a challenging task. A cost-estimating procedure for predicting spatial variability must be able to automatically derive the cost-driving characteristics of road components for any specific location within a project area, and to analyze cost per unit of road length based on their unit-cost information.

Identification of the building components for lowvolume roads follows a standardized WBS (Westney 1997) within the construction industry, i.e., the cost classification by elements (CCE) approach (CCE 1991). This method consists of three hierarchical levels: (1) the macro element, (2) the element group, and (3) the element level. For preliminary planning, Level 2 is an appropriate decomposition that accommodates four element groups: embankment structure, supporting and retaining structures, pavement structure, and drainage and stream-crossing structures. A standard design crosssection defines the structural dimensions in terms of crown, surface, ditch, and shoulder width, cut-and-fill slope angles, and retaining wall specifications (Fig. 1). To verify how those element groups affect construction costs, we assessed five low-volume projects carried out under different slope conditions in Switzerland (Fig. 2). There, the cost for the embankment structure (A) depended heavily on the slope gradient, whereas the cost for supporting and retaining structures (B) seemed to be relevant for slope gradients $>50 \%$. The costs for pavement (C) and drainage structure (D) were somewhat variable, as explained by the bearing capacity of the subsoil and by the design standard. For example, our second study site, "Prabé Sud", is situated in limestone in the central Swiss Alps with heavy rainfalls, where its asphalt concrete surface course incurred high construction costs. This preliminary, approximate analysis clearly indicated that slope gradient is the leverage factor for an analytical cost model. Additionally, the shear strength of the subsoil is critical to the design of cut-andfill slopes (Coulomb 1776; Terzaghi 1944), as well as for the design of the pavement structure (AASHTO 1993). Therefore, spatial information about geotechnical soil properties must be included if road engineers are to improve the accuracy of cost modeling.

\section{Embankment model}

Design engineers can choose among full-bench, selfbalanced, or retaining-wall cross sections. Therefore, our current analysis combined the element groups "embankment" and "retaining" structures. The embankment model was aimed at calculating the excavation volume of a standard cross section at any location within a project area (Fig. 3). This model assumed (1) the slope angle of the terrain $(\eta)$ to be constant for the whole cross section, (2) the cut-and-fill volume to be self-balanced, (3) the angles for cut-and-fill slopes to be determined by the geotechnical properties of the subsoil, (4) consolidation of cut-and-fill slope material to differ, and (5) the bedrock surface to be parallel to the terrain surface. Loosening and loss of fill-slope material was assessed with a shrinking factor $\left(f_{\text {shr }}\right)$ that depended on subsoil geotechnical properties.

Because the cut-slope angle $\left(\phi_{\text {cut }}\right)$ is most often higher than that of the fill slope $\left(\phi_{\text {fill }}\right)$, the self-balanced design required the axis to be shifted horizontally in uphill direction (Fig. 3). However, if the slope angle had become equal to or larger than the fill-slope angle, the road would then have needed to be built according to a full- 


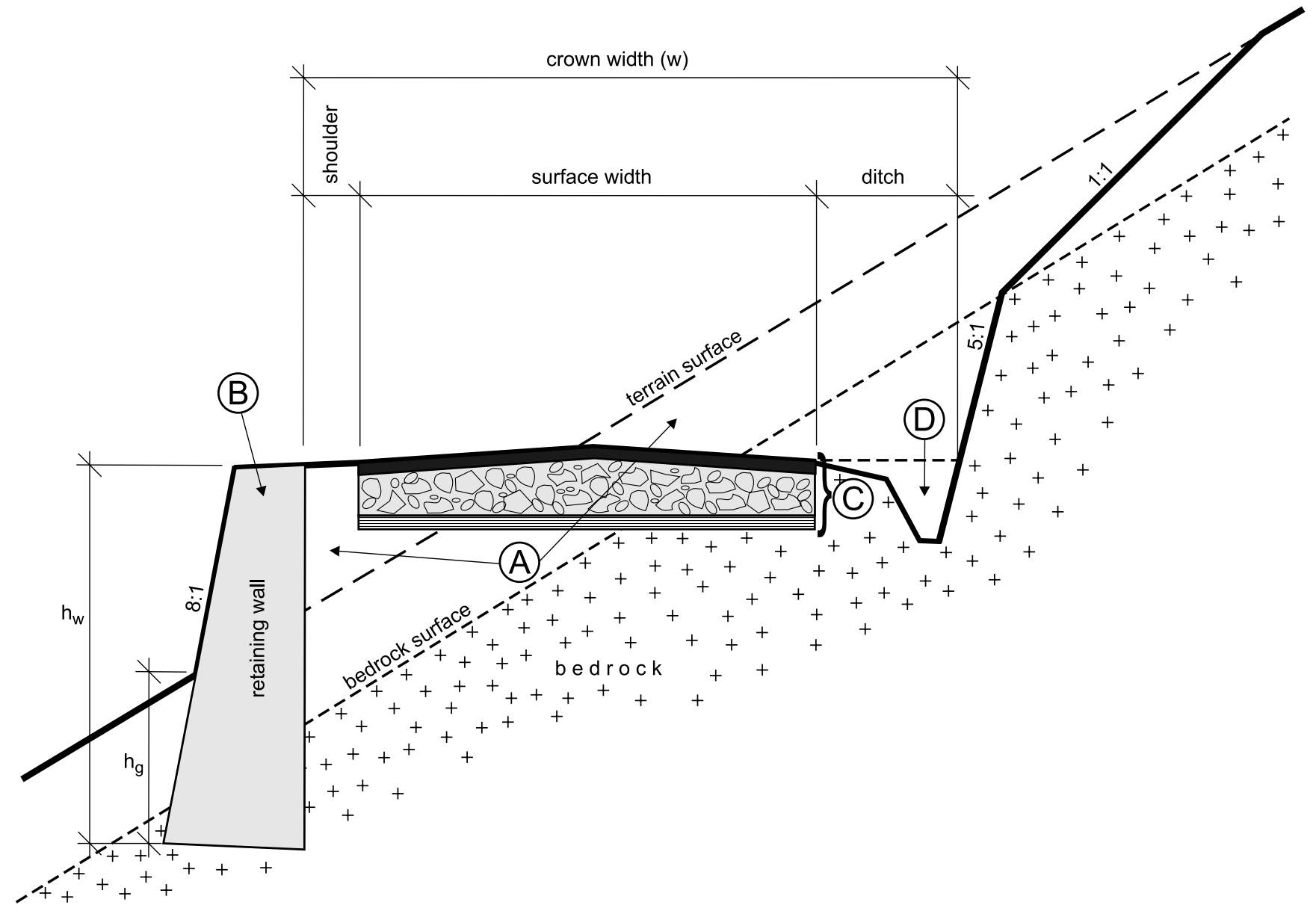

Fig. 1 Standard design cross-section with four element groups: (A) height of retaining wall, $h_{\mathrm{g}}$ depth of foundation of retaining wall, $w$ embankment structure, (B) retaining structures, (C) pavement structure, and (D) drainage and stream-crossing structures. $h_{\mathrm{w}}$ crown width (surface + shoulder + ditch). Figure is not drawn to scale, especially in shoulder and ditch dimensions

Fig. 2 Cost of element groups in relation to slope gradient. All values are in Swiss francs (CHF), adjusted to price level for Year 2000

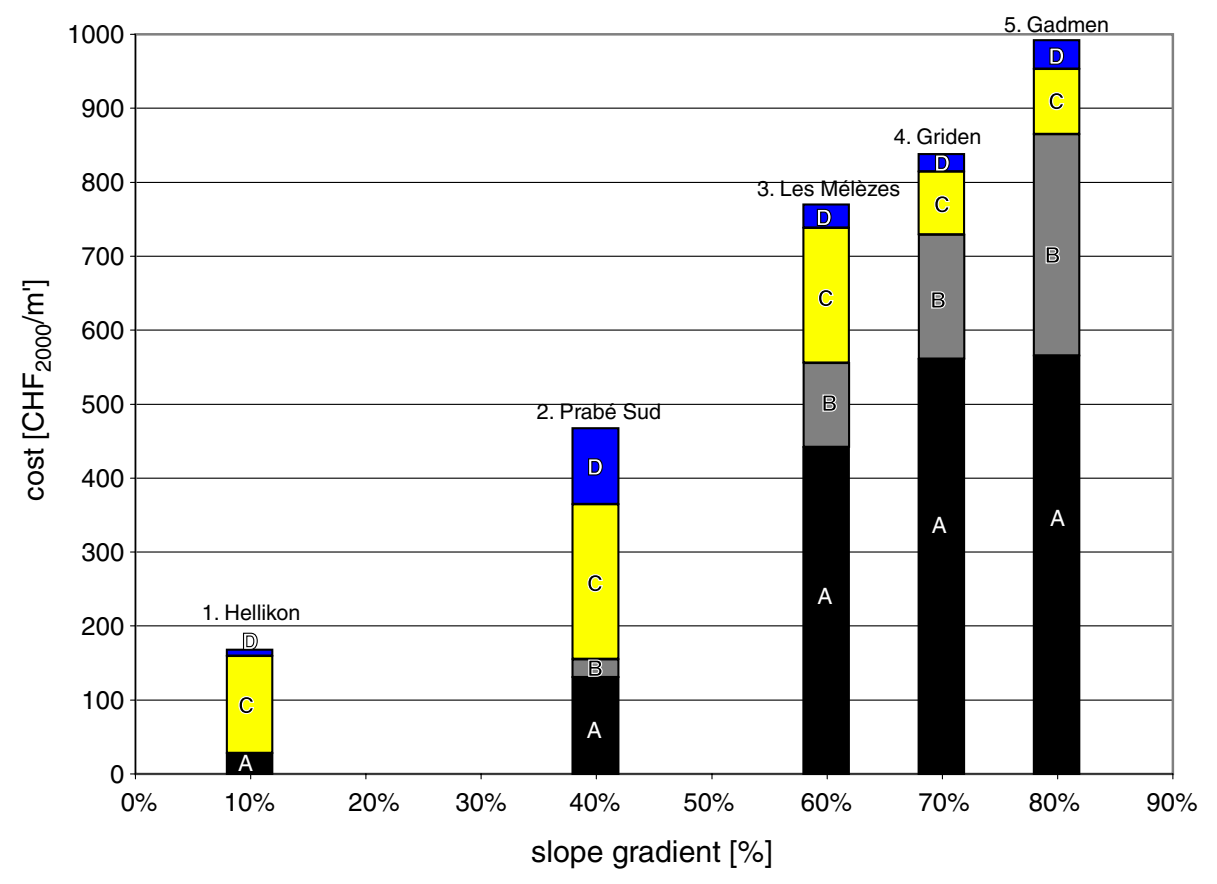




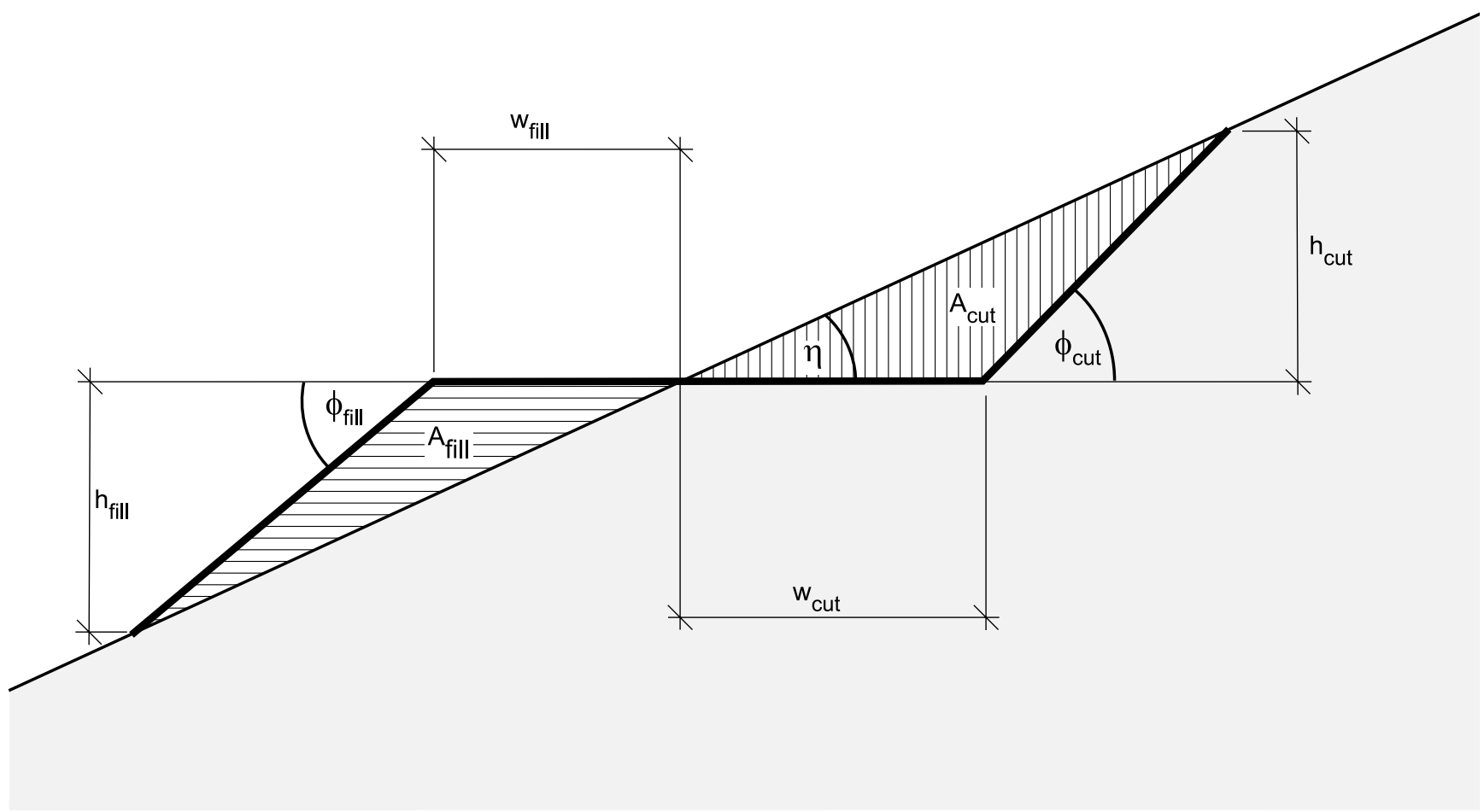

Fig. 3 Standard design cross-section of low-volume road. $A_{\text {cut }}$ cutslope area; $A_{\text {fill }}$ fill-slope area; $h_{\text {cut }}$ cut-slope height; $h_{\text {fill }}$ fill-slope height; uphill side; $w_{\text {cut }}$ road width, uphill side; $w_{\text {fill }}$ road width, downhill side; $\eta$ slope angle, depending on terrain surface; $\phi_{\text {cut }}$ cut angle, depending on geotechnical properties; and $\phi_{\text {fill }}$ fill angle, depending on geotechnical properties bench design. Heinimann (1998) has devised Eqs. 1, 2, and 3 to calculate excavation volumes for the conditions and constraints mentioned above; these equations are valid only for positive slope angles. Nevertheless, on a digital elevation model (DEM), values for slope gradient may also be negative. Therefore, our algorithmic implementation had to be robust, which required a more detailed model formulation as follows:

$$
\begin{aligned}
A_{\text {cut }}= & \frac{w_{\text {cut }}^{2} \times \tan \left(\phi_{\text {cut }}\right) \times \tan (\eta)}{2\left(\tan \left(\phi_{\text {cut }}\right)-\tan (\eta)\right)}>0 \\
A_{\text {fill }}= & \frac{\left(w-w_{\text {cut }}\right)^{2} \times \tan \left(\phi_{\text {fill }}\right) \times \tan (\eta)}{2\left(\tan \left(\phi_{\text {fill }}\right)-\tan (\eta)\right)}>0 \\
f_{\text {shr }}= & \frac{A_{\text {fill }}}{A_{\text {cut }}} \leq 1 \\
& w_{\text {cut }}^{2} \times \underbrace{\left(\frac{\tan \left(\phi_{\text {cut }}\right) \times f_{\text {shr }}}{\tan \left(\phi_{\text {cut }}\right)-\tan (\eta)}-\frac{\tan \left(\phi_{\text {fill }}\right)}{\tan \left(\phi_{\text {fill }}\right)-\tan (\eta)}\right)}_{a} \\
& +w_{\text {cut }} \times \underbrace{\frac{2 w \times \tan \left(\phi_{\text {fill }}\right)}{\tan \left(\phi_{\text {fill }}\right)-\tan (\eta)}}_{a}+\underbrace{\frac{w^{2} \times \tan \left(\phi_{\text {fill }}\right)}{\tan (\eta)-\tan \left(\phi_{\text {fill }}\right)}}_{c}=0
\end{aligned}
$$$$
w_{\text {cut }}=\frac{-b \pm \sqrt{b^{2}-4 a c}}{2 a} .
$$

To make the analytical explanation easily understandable, only positive slope gradients were considered in
Eqs. 1, 2, 3, 4, 5, 6, 7, 8, and 9. Cut-slope and fill-slope angles $\left(\phi_{\text {cut }}\right.$ and $\left.\phi_{\text {fill }}\right)$ had to be greater than ground slope $(\eta)$ because of geometrical constraints. Here, we examined three different cases in terms of variable $a$ (Eqs. 5, 6): (1) fill-slope angles larger than cut-slope angles, (2) cut-slope angles greater than fill-slope angles, and (3) fill-slope angles equal to cut-slope angles. In the first case, the resulting value was less than zero $(a<0)$. Therefore, the root term of Eq. 5 was the limiting factor, and the discriminate $d$ had to be positive (Eq. 6), thereby resulting in Eq. 7.

$d=b^{2}-4 a c>0$

$d=\frac{4 w^{2} \times \tan \left(\phi_{\text {fill }}\right) \times \tan \left(\phi_{\text {cut }}\right) \times f_{\text {shr }}}{\left(\tan \left(\phi_{\text {fill }}\right)-\tan (\eta)\right)\left(\tan \left(\phi_{\text {cut }}\right)-\tan (\eta)\right)}>0$.

All factors in the numerator of Eq. 7 were positive, and both $\phi_{\text {cut }}$ and $\phi_{\text {fill }}$ were always greater than $\eta$. Hence, the formulation was correct for any possible case. Likewise, because the negative branch of the root term in Eq. 5 led to values greater than $w$, only the positive branch of the root term was feasible.

The second case dealt with fill angles smaller than cut angles $(a>0)$. In most case, however, geotechnical stability required the latter to exceed the former. Assuming that, in some cases, the fill angles were smaller, the root term in Eq. 5 become smaller than $b$. As a consequence, only the positive branch of the root term resulted in feasible solutions. 
The third case considered fill angles equal to cut angles $(a=0)$. The conditions for this case follow from Eq. 8. Furthermore, for a self-balanced design the cutroad width was equal to the fill-road width (Eq. 9).

$$
\begin{aligned}
& f_{\text {shr }} \times \tan \left(\phi_{\text {cut }}\right)\left(\tan \left(\phi_{\text {fill }}\right)-\tan (\eta)\right) \\
& \quad-\tan \left(\phi_{\text {fill }}\right)\left(\tan \left(\phi_{\text {cut }}\right)-\tan (\eta)\right) \\
& \quad=0 \\
& w_{\text {cut }}=w_{\text {fill }}=-\frac{c}{b}=\frac{w}{2}
\end{aligned}
$$

Equations 1, 2, 3, 4, 5, 6, 7, 8, and 9 are analogously applicable for negative slope gradients $(\eta<0)$. However, in these cases cut-slope and fill-slope angles $\left(\phi_{\text {cut }}\right.$ and $\left.\phi_{\text {fill }}\right)$ had to be more negative than ground slope angle $(\eta)$ because of geometrical constraints.

When one knows the relation of $w_{\text {cut }}$ to $w_{\text {fill }}$, one can then calculate self-balanced cut-and-fill volumes for each location in the project area. However, such a cross-section design is not always the most appropriate. Full bench is a second option for cross-section design, increasing embankment stability in steep terrain or unstable subsoil conditions by shifting the road structure horizontally in the uphill direction. As the third option for cross section, the retaining-wall design locates those structures on either the uphill or downhill side of the road. We used a lookup table to define the critical terrain slope figures for each geotechnical unit as well as to discriminate among these three cross-section design solutions (c.f., geotechnical parameters).

In difficult terrain conditions, part of the excavation volume may be of rock. Practical experience in Switzerland has shown that the unit cost for its excavation is approximately four to five times greater than for the removal of soil alone. Inaba et al. (2001) have developed an empirical model to estimate the share rock excavation as a function of slope, a coefficient for each geological unit ( coef $_{\text {rock }}$ ), and crown width for low-volume roads (Eq. 10). For the current study, we determined the share of rock for cut-slope areas in three groups of geological formations, all with crown widths of $4.10 \mathrm{~m}$ (Fig. 4). The first group comprised mesozoic and tertiary sediment formations, typical of the northern slopes of the Alps, and included conglomerate, sandstone, limestone, and flysch. The second group consisted of intrusive and the metamorphic rock formations - granite and gneissthat are typical for the central and southern slopes of the Alps. The third group consisted of quaternary formation such as moraine and alluvial deposit. For slope gradients of up to approximately $40 \%$, the necessary volume of rock excavation was of minor importance and could be easily neglected. At gradients of $70 \%$, about one-third of the volume was rock; at gradients of about $90 \%$, twothirds consisted of rock. In general, the rock excavation volume was calculated as the product of the cut-slope volume multiplied by the rock share factor (Fig. 4).

$$
\begin{aligned}
& \operatorname{logit}=-6.69+\operatorname{coef}_{\text {rock }}+(4.913+0.396 \times \tilde{w}) \\
& \times \tan (\eta)^{0.6} \\
& p_{\text {rock }}=\frac{e^{\text {logit }}}{1+e^{\text {logit }}}
\end{aligned}
$$

where

coef $_{\text {rock }}$ geological parameter for rock ratio estimation (c.f., Table 1)

$\eta \quad$ slope gradient

$e \quad$ the Euler number

logit interim result for logit-function

$p_{\text {rock }} \quad$ share of rock in total cut area $[0 \ldots 1]$

$\tilde{w}$ the dimensionless numerical value of the road crown width in meter.

The total costs for earthwork and embankment preparation for a road segment depended on both the earth excavation volume $\left(V_{\text {cut }}\right)$ and rock excavation volume $\left(V_{\text {rock }}\right)$. Volume was approximated by the frustum of a pyramid (Eq. 11), whereas the total embankment cost was determined with Eq. 12.
Fig. 4 Share of rock excavation for low-volume road (crown width $=4.10 \mathrm{~m}$ ), as a function of slope gradient and type of geological formation

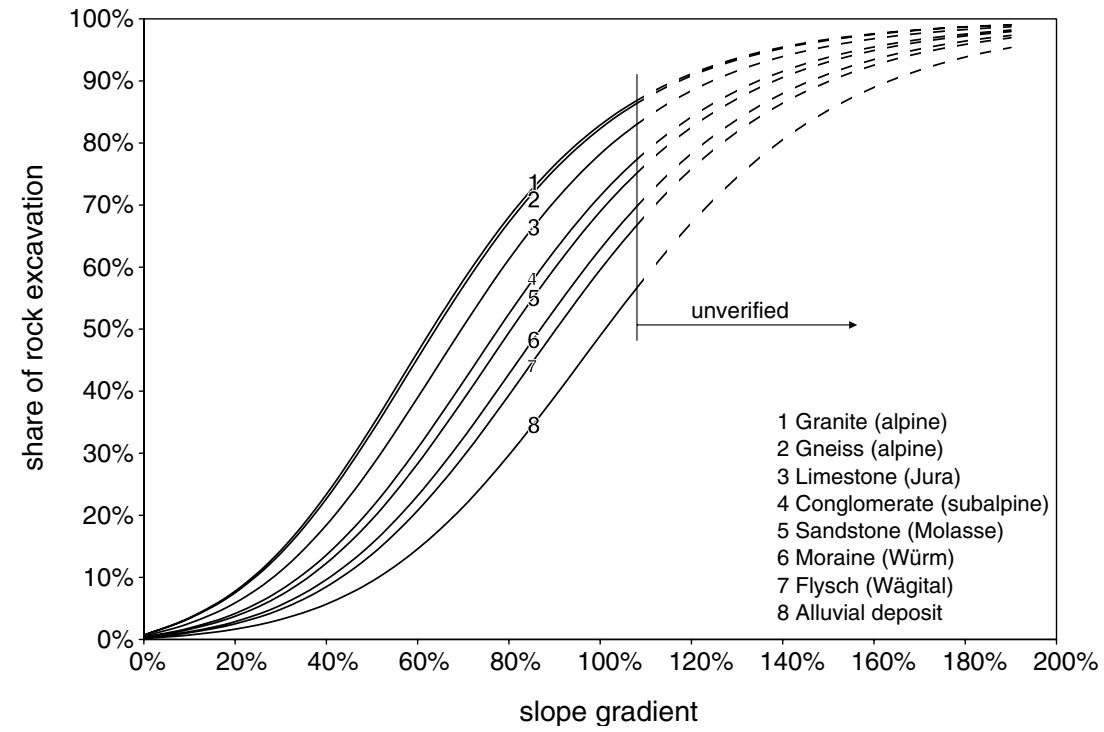




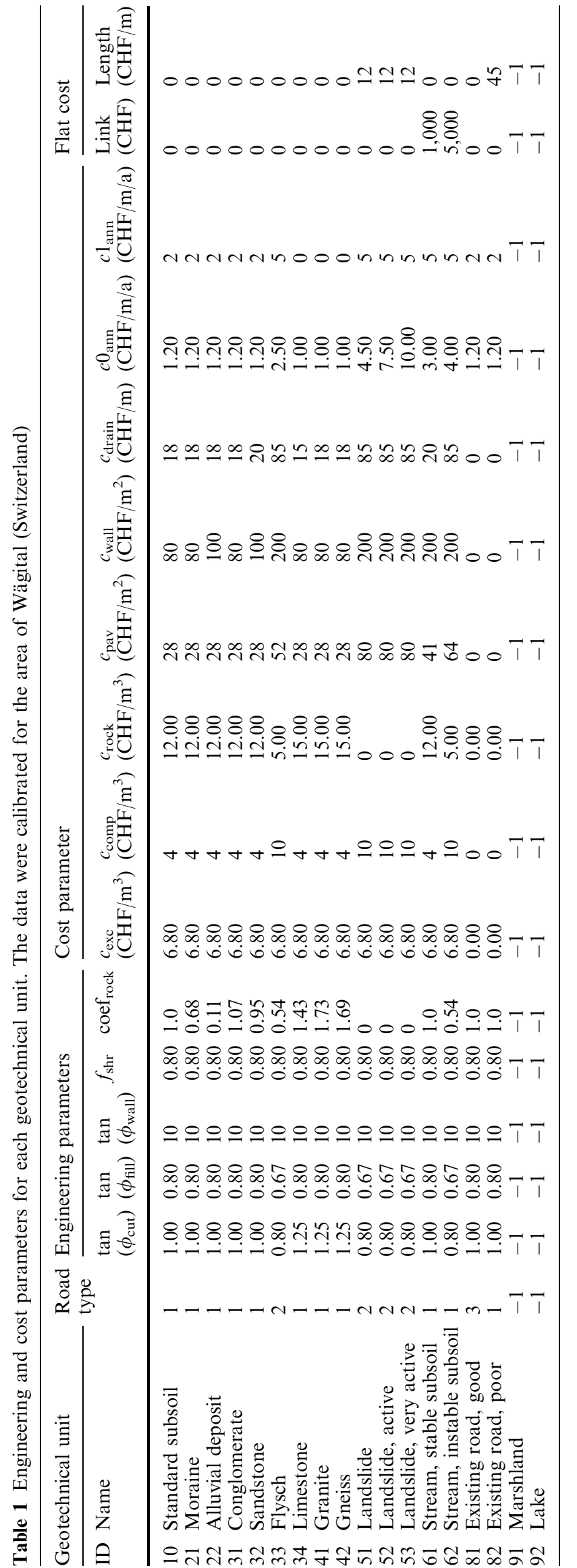

$V=\frac{l}{3}\left(A_{0}+\sqrt{A_{0} \times A_{1}}+A_{1}\right)$

where

$A_{0} \quad$ area (either fill or cut) of the initial cross-section

$A_{1}$ area (either fill or cut) of the following crosssection

$l \quad$ middle length of the arc of the segment

$V \quad$ volume (either fill or cut)

$C_{\text {emb }}=V_{\text {fill }} \times c_{\text {comp }}+V_{\text {cut }}\left(c_{\text {exe }}+p_{\text {rock }} \times c_{\text {rock }}\right)$

where

$c_{\text {comp }} \quad$ cost for compaction per volume unit

$C_{\text {emb }}$ embankment cost

$c_{\text {exc }} \quad$ excavation cost per volume unit

$c_{\text {rock }}$ extra cost for rock excavation per volume unit

$p_{\text {rock }} \quad$ share of rock in total cut area [0...1]

$V_{\text {cut }} \quad$ cut volume

$V_{\text {fill }} \quad$ fill volume.

\section{Retaining structure model}

In difficult terrain conditions (e.g., steep slopes, unstable soil conditions), retaining structures are necessary to provide safe embankments. Assuming that the slope gradient could be extracted automatically from a DEM, and that preference rules indicated a retaining-wall cross-section design, we then calculated the height $\left(h_{\mathrm{w}}\right)$ (Fig. 1) and length of the retaining wall. Additional height $\left(h_{\mathrm{g}}\right)$ used for the foundation was presumed to be constant. The cost for a retaining wall was assumed to be proportional to its height times length (Eq. 13), a rule that seems appropriate for heights of up to $3 \mathrm{~m}$.

$C_{\mathrm{wall}}=\left(h_{\mathrm{w} 1}+h_{\mathrm{w} 2}+2 \times h_{\mathrm{g}}\right) \times l \times c_{\mathrm{wall}}$

where

$c_{\text {wall }} \quad$ cost for retaining wall per unit area

$C_{\text {wall }} \quad$ cost for retaining wall

$h_{\mathrm{w} 1}, \quad$ height of retaining walls (uphill and downhill

$h_{\mathrm{w} 2}$ sides)

$h_{\mathrm{g}} \quad$ constant value for foundation and clearance of retaining wall (in the present $\operatorname{model}=1 \mathrm{~m}$ )

$l \quad$ length of road segment

\section{Pavement structure model}

The cost of pavement structures is assumed to be proportional to numerous variables, including the surfaced road area for specific soil-bearing conditions, expected traffic volume, and the aggregate materials used for the sub-base, the base course, and the surface course. To design the pavement structure, we adapted AASHTO procedures to the special requirements for low-volume roads in Switzerland (Burlet 1980). In Eq. 14, both a 
standard road width and widening at curves and switchbacks were considered.

$C_{\mathrm{pav}}=\left(w_{\mathrm{s} 0}+\frac{k_{\mathrm{cw}}}{r}\right) \times l \times c_{\mathrm{pav}}$

where

$\begin{array}{ll}c_{\text {pav }} & \text { cost for pavement per unit area } \\ C_{\text {pav }} & \text { cost for pavement structure } \\ k_{\mathrm{cw}} & \begin{array}{l}\text { constant value for road widening in curves (in } \\ \text { the present model, }=26 \mathrm{~m} \text { ) }\end{array} \\ l & \text { length of road segment } \\ r & \text { curve radius } \\ w_{\mathrm{s} 0} & \text { standard road surface width }\end{array}$

\section{Drainage and stream-crossing structures}

The cost for drainage structures, such as ditches or culverts, was assumed to be proportional to road length (l) (Eq. 15). Ditch relief culverts ideally are arranged at constant $50-\mathrm{m}$ intervals, but would be unnecessary on flat terrain $(<12 \%)$. Three principal types of streamcrossing structures are available: bridge, culvert, and ford, the last type being the only one automatically considered in the present model. Its construction incurred a higher cost due to the hardening measures of the surface, extra drainage (e.g., a culvert at the vertex location in the channel), and additional retaining structures. The unit cost for a ford presumably depends on geology and size of the area defined by its location.

$$
C_{\text {drain }}= \begin{cases}0 & \text { if } \tan (\eta)<12 \% \\ \frac{C_{\text {culvert }}}{d} \times l & \text { else }\end{cases}
$$

where

$C_{\text {culvert }}$ cost for single culvert

$C_{\text {drain }}$ cost for drainage structure

$d$ distance between ditch relief culverts (in the present model $=50 \mathrm{~m}$ )

$l \quad$ length of road segment

\section{Life-cycle cost model}

Life-cycle costs entail those for construction, routine and periodic maintenance, rehabilitation, and decommissioning. The model analyzed here did not consider the last two factors, and assumed the maintenance cost to be dependent only on road gradient and geology. This assumption, however, differs from practices in USA and in Canada, where thresholds for total traffic volume trigger periodic maintenance.

To make these cost components comparable, they must be normalized in time. Net present value (NPV), annual equivalent rate (AER), and internal rate of return (IRR) are measures commonly used for obtaining the time value of money. Our model followed the NPV approach, assuming a project life cycle of 50 years, an interest rate of $2 \%$, and a constant share in maintenance costs per year. Equations 16 and 17 are widely applied in engineering economics (Heinimann 1998; Park and Sharp-Bette 1990).

$C_{\text {ann }}=C_{\text {reg }}+\frac{C_{\text {peri }}}{n}$

$C_{\mathrm{tot}}=C_{\mathrm{con}}+C_{\mathrm{ann}} \times\left(\frac{1-(1+i)^{-N}}{i}\right)$

where

$\begin{array}{ll}C_{\text {ann }} & \text { average annual maintenance cost } \\ C_{\text {con }} & \text { construction cost } \\ C_{\text {per }} & \text { periodical maintenance cost } \\ C_{\text {reg }} & \text { regular maintenance cost } \\ C_{\text {tot }} & \begin{array}{l}\text { total cost for a single road segment } \\ i\end{array} \\ n & \begin{array}{l}\text { annual interest rate (in the present model }=2 \% \text { ) } \\ \text { periodical-maintenance interval (in the present }\end{array} \\ N & \begin{array}{l}\text { model }=5 \text { years) } \\ \text { amortization period of the road (in the present } \\ \text { model }=50 \text { years) }\end{array}\end{array}$

Curve and switchback model

Detailed road engineering defines the horizontal layout of a road as a consecutive set of straight lines and curves, whereas computer-aided preliminary planning tools usually use a traverse representation, consisting of a continuous series of lines. The latter approach has two shortcomings (see Heinimann et al. 2003). First, the road length for curves is shorter than the tangent distance, and the road does not widen (c.f., Eq. 14). Second, a change in direction of $>135^{\circ}$ requires a "hairpin bend" embankment structure, called a switchback. Constructing a switchback always involves considerable additional earthwork and surfacing, resulting in significantly higher total cost. The balancing of cut-and-fill volumes is not possible for a single cross-section of a switchback, but must be achieved between the beginning and the end of the switchback curve. Figure 5 shows that, depending on the central angle $(\gamma)$, our procedure for calculating switchback costs required several intermediate cross-sections. The best possible volume balance was then identified by shifting the switchback center orthogonally to the contour lines, at a step width of $0.5 \mathrm{~m}$ and within an interval of $-5 \mathrm{~m}$ to $+5 \mathrm{~m}$. This procedure was similar to one proposed by Aruga et al. (2004).

Organization of input data

\section{Data model}

One purpose of the present model was to derive costdriving features automatically from a geographical database. This database, represented by $10 \times 10-\mathrm{m}$ cells, 
Fig. 5 Road segments of switchbacks, a $\gamma$ central angle $=180^{\circ}$ ), $\mathbf{b} \gamma$ central angle $=220^{\circ}$. Each switchback starts and ends at regular nodes (bold point symbols). The centerline is subdivided into 6 (a) or 10 (b), respectively, intermediate sections (slim point symbols). Regular nodes are fixed whereas locations of intermediate nodes depend on the location of the center as well as $\gamma$
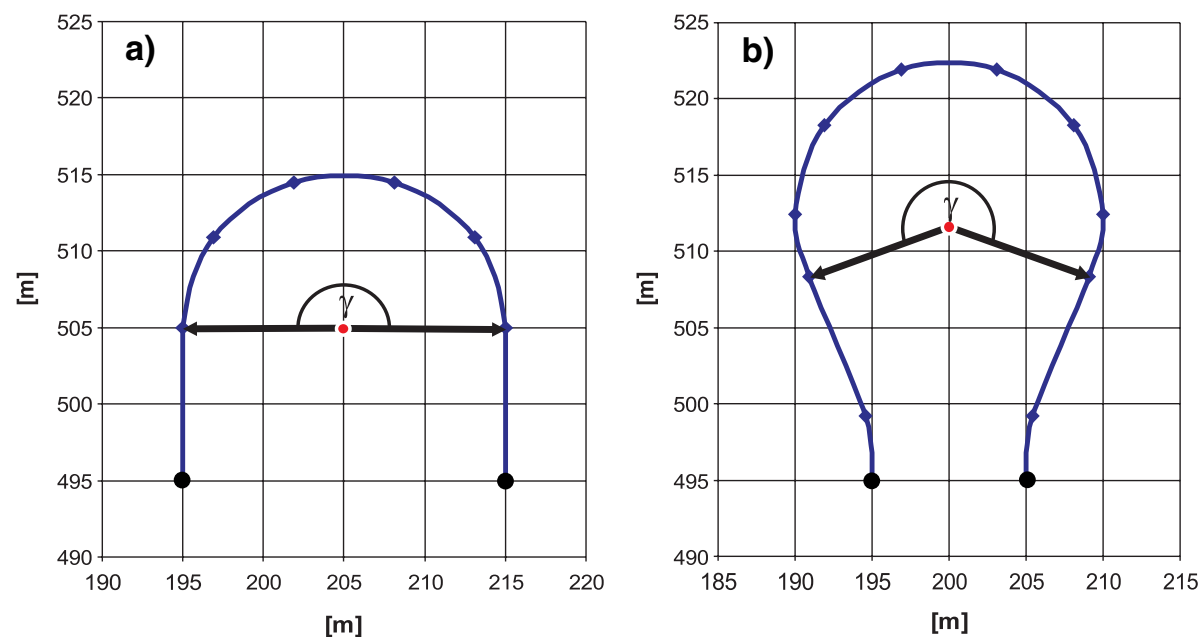

had two layers: (1) a DEM of the terrain surface, and (2) a geotechnical classification of the subsoil. A first lookup table specified the engineering and cost properties for each geotechnical unit. A second lookup table defined the design elements of a standard cross-section for each geotechnical unit. Figure 6 shows an entity-relationship model of the data. This data structure makes it possible to adapt the model to any area specific conditions in the world as long as the road can be modeled by the four element groups explained in section cost estimation framework.

\section{Geotechnical parameters}

Engineering and cost properties are specific for each geotechnical unit. Site specific parameters are stored as a record in a data base table consisting of five engineering properties [cut-slope inclination $\left(\tan \left(\phi_{\text {cut }}\right)\right)$, fill-slope inclination $\left(\tan \left(\phi_{\text {fill }}\right)\right)$, inclination of retaining wall $\left(\tan \left(\phi_{\text {wall }}\right)\right)$, shrinking factor $\left(f_{\text {shr }}\right)$, and a coefficient for rock ratio estimation (coef rock$_{\text {) }}$, c.f., Eq. 10], six parameters for construction costs [excavation cost $\left(c_{\text {exc }}\right)$, cost for emplacement and compaction of the filling material $\left(c_{\text {comp }}\right)$, additional cost for rock excavation $\left(c_{\text {rock }}\right)$, cost for pavement structures $\left(c_{\text {pav }}\right)$, cost for retaining walls $\left(c_{\text {wall }}\right)$, and cost for drainage structures $\left.\left(c_{\text {drain }}\right)\right]$, and two parameters for maintenance [constant cost per road length $\left(c 0_{\mathrm{ann}}\right)$, and variable cost proportional to the road gradient $\left(c 1_{\mathrm{ann}}\right)$ and road length].

Special terrain types (e.g. landslides, stream crossings, rehabilitation of existing roads) may require additional cost parameters. These parameters can be defined by flat
Fig. 6 Entity-relationship model for the input data

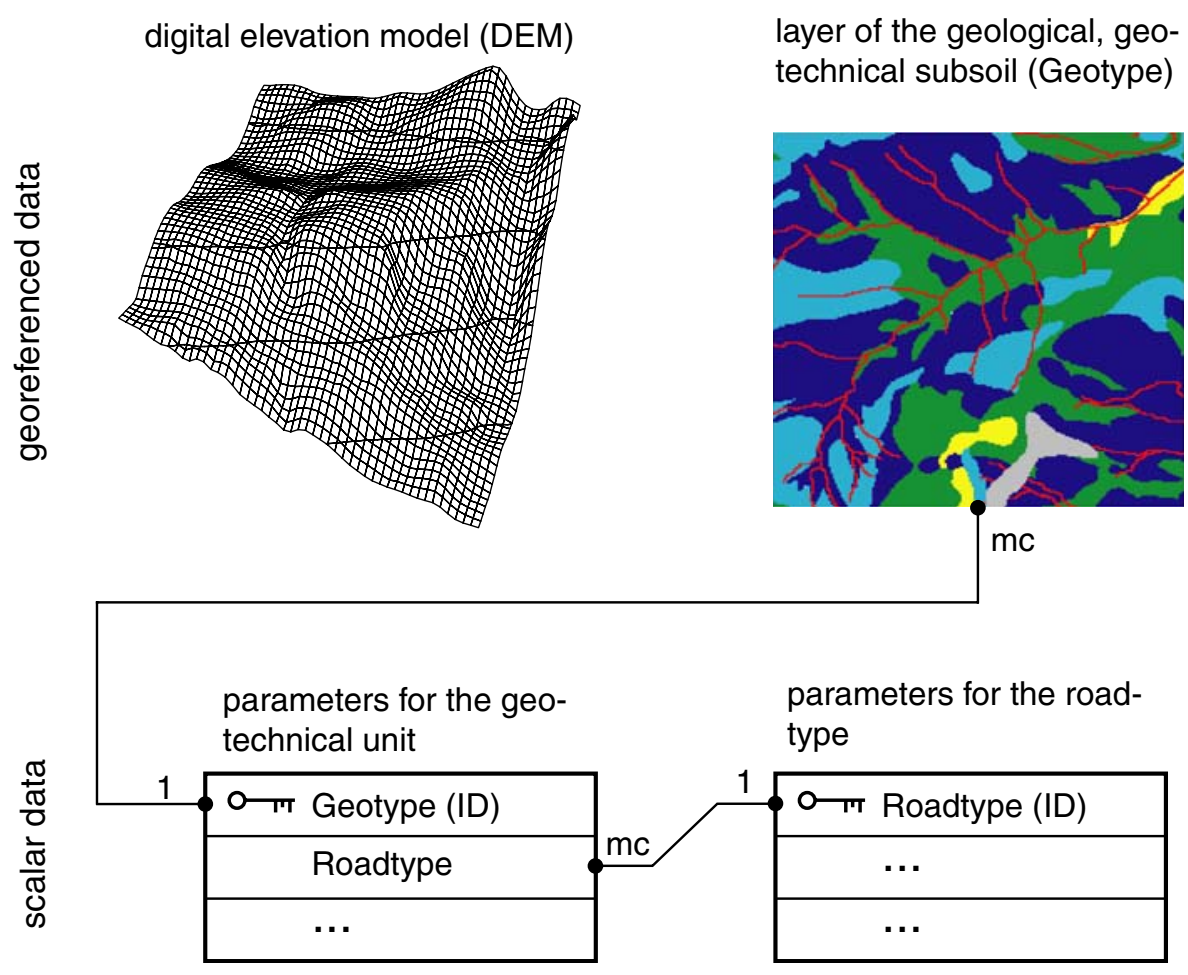


Table 2 Design parameters for each road type used in the area of Wägital (Switzerland)

\begin{tabular}{|c|c|c|c|c|c|c|c|c|}
\hline \multicolumn{2}{|c|}{ Road type } & $v_{\max }(\mathrm{m})$ & $r_{\min }(\mathrm{m})$ & $r_{\mathrm{SB}}(\mathrm{m})$ & $w_{\mathrm{s} 0}(\mathrm{~m})$ & $w_{\mathrm{d}+\mathrm{s}}(\mathrm{m})$ & $k_{\mathrm{cw}}\left(\mathrm{m}^{-2}\right)$ & $z_{\min }(\mathrm{m})$ \\
\hline 1 & Standard road & 0.12 & 20 & 10 & 3.4 & 0.6 & 26 & 0.30 \\
\hline 2 & Road in instable & 0.10 & 20 & 10 & 3.4 & 0.6 & 26 & 0.50 \\
\hline 3 & Existing road & 0.20 & 10 & 5 & 3.4 & 0.6 & 13 & 0.30 \\
\hline
\end{tabular}

cost per link or flat cost per length. Sites where construction is impossible (e.g. lake, marshland) are represented by negative values.

Construction processes (full mechanized, low mechanized, labor intensive) are represented by cost values only that may be obtained by analyses of contractor bids, engineering estimation, or final costing analysis. Table 1 shows all geological parameters used in the area of Wägital (c.f., model evaluation).

\section{Road parameters}

The model assumes one predominant road type for a specific project area. However, the designer may specify different design parameters, e.g. a smaller road width in rocky terrain are, or a less maximum, road gradient in instable subsoil. The road type is linked to the geotechnical unit and defined by the parameters maximal allowable road gradient $\left(v_{\max }\right)$, minimal radius in curves $\left(r_{\text {min }}\right)$ and switchbacks $\left(r_{\mathrm{SB}}\right)$, standard road surface width $\left(w_{\mathrm{s} 0}\right)$, width for ditch and shoulders $\left(w_{\mathrm{d}+\mathrm{s}}\right)$, road widening in curves $\left(k_{\mathrm{cw}}\right)$, and minimal excavation depth for pavement structures $\left(z_{\min }\right)$. Table 2 shows all road design parameters used in the area of Wägital (c.f., model evaluation).

\section{Model implementation}

Our procedures were implemented via Borland Delphi 7.0 software (Object Pascal language), which produced approximately 3,700 lines of code. Input and output data consisted entirely of text files that could be easily imported from or exported to commercial geographical information systems, such as ESRI ArcGIS. At present, this implementation can handle areas of up to $100 \mathrm{~km}^{2}$, with $10 \times 10 \mathrm{~m}$ raster cells. The model split the road route into $10-\mathrm{m}$ segments for straight lines and curves, and 2$\mathrm{m}$ sections for switchbacks. Procedures for optimizing the road network were implemented in a separate program unit, which was previously described by Stückelberger et al. (2004).

\section{Validation and evaluation}

Model validation

Validation was aimed at demonstrating that our model reasonably represented the cost of low-volume road projects. It required high-quality cost data normally available only after a project is completed. However, a full validation that investigates assumptions, input parameters, and output values is difficult to achieve. Therefore, compromises were necessary, resulting in a preliminary validation approach.

In this current study, validation was performed for projects on two different geological formations. The first covered an area in the molasse zone; the second, in limestone. Both were located on the northern slopes of the Swiss Alps. The first part of the validation compared the excavation volumes produced by the model with those values obtained from actual, detailed road projects, as engineered by students in the molasse zone. The second part occurred in the limestone zone, and was mainly focused on investigating rock excavation volumes and costs. Decisive figures from real-world cases were extracted from engineering documentation, especially technical reports and cost estimates. Application of the model required us to specify the design element and the unit-cost parameters, both of which were stored in a lookup table linked to the geology layer of the spatial database (Fig. 6).

The first part of the validation demonstrated that our model accurately estimated the excavation volume. However, it also showed that a $10 \times 10-\mathrm{m}$ representation resulted in inaccurate estimates for stream channel or terrain edge locations. For the second part, data obtained from the engineering documentation were compared with the model output (Table 3). Here, the model overestimated the total embankment volume by about $16 \%$, seemingly favoring a full-bench cross-section design. In contrast, the road engineers preferred a retaining-wall cross-section design, which was represented by a much higher cut-slope volume predicted by the model. Cost figures showed that the model estimate for the embankment structure was within the range of accuracy $( \pm 10 \%)$, while the engineer's estimate for the pavement structure was about $20 \%$ higher. Although the road engineer planned for additional turnouts and other areas to be surfaced with aggregate material, if those factors were neglected, costs for the pavement structure were more or less identical. The usefulness of our validation results was limited because they were based on a comparison of estimates from an engineer versus a model. A more reliable validation would have required accurate post-construction information on design-element unit quantities and unit cost, which is usually not available. 
Table 3 Comparison of excavation and cost figures for two alternatives: (1) results of engineering project design and contractor bid versus (2) model results

\begin{tabular}{llllll}
\hline & Item & Unit & Project bid & Model & Relative Difference \\
\hline Earth work & Cut volume & $\mathrm{m}^{3}$ & 1,929 & 2,720 & $+41 \%$ \\
& Fill volume & $\mathrm{m}^{3}$ & 1,042 & 7,21 & $-31 \%$ \\
Cost & Total volume & $\mathrm{m}^{3}$ & 2,971 & 3,441 & $+16 \%$ \\
& Embankment and retaining structures & $\mathrm{CHF}$ & 78,465 & 85,648 & $+9 \%$ \\
& Pavement structure & $\mathrm{CHF}$ & 59,200 & 45,900 & $-23 \%$ \\
& Drainage and stream-crossing structures & CHF & 13,180 & 17,880 & $+36 \%$ \\
& Total cost & CHF & 150,845 & 149,428 & $-1 \%$ \\
\hline
\end{tabular}

Costs, in Swiss francs (CHF), are adjusted to price level for Year 1997

Fig. 7 Spatial variability in road life cycle costs for Scenario III, based on slope gradient and geotechnical soil properties. The lake "Wägital" $\left(35 \mathrm{~km}^{2}\right)$ is at eastern boundary and watershed is at western boundary

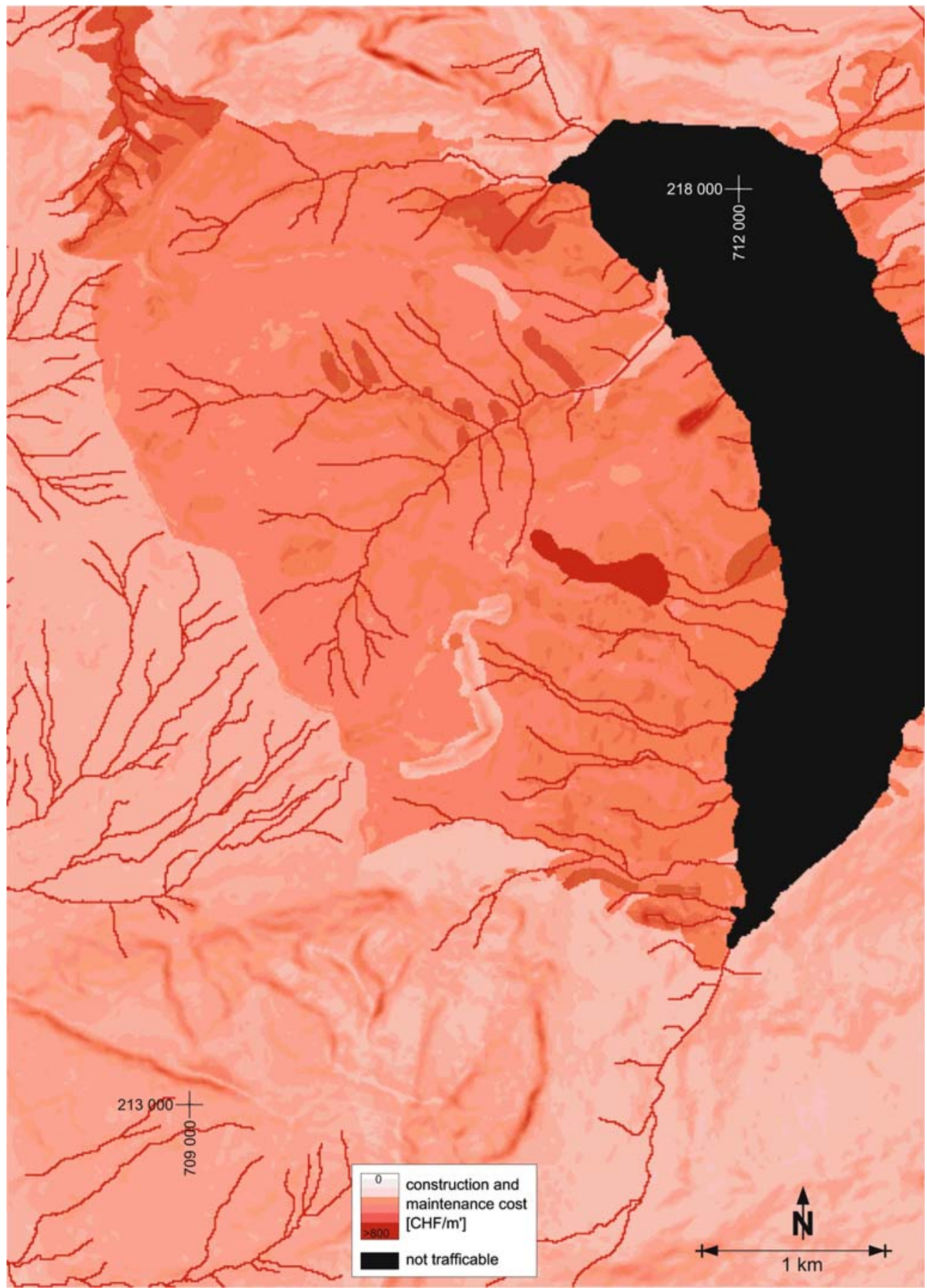


Fig. 8 Variability of life-cycle cost per unit for Scenario I, II, and III. The curves show the cumulated frequency of the and maintenance costs for each scenario project area to the construction

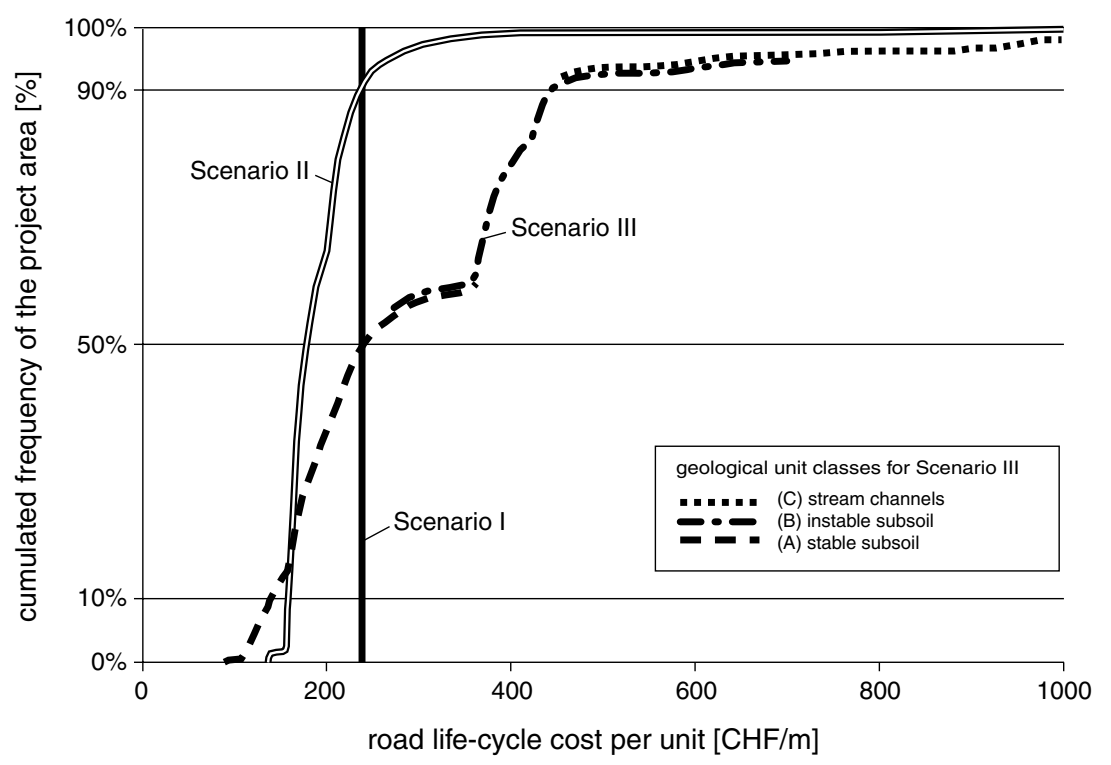

3. Scenario III, which considered both slope gradient and geotechnical information as decisive parameters as well as different road types for cost variability. All design and cost parameters are shown in Tables 1 and 2.

Scenario I served as a reference for the engineering practices currently used to estimate costs at a preliminary planning stage.

\section{Results and discussion}

The "Wägital" project site is located on the northern slopes of the Swiss Alps, in flysch and limestone zones. This area is characterized by extremely difficult geotechnical conditions, such as low soil-bearing capacity (CBR values $<3 \%$ ), unstable terrain with many landslides, and a dense channel network. Evaluation was based on three cost-estimating scenarios:

1. Scenario I, which assumed construction costs to be route-independent $(240 \mathrm{CHF} / \mathrm{m})$ and constant for the entire project area. The design parameters (minimum curve radius $\left(r_{\mathrm{min}}\right)$, maximal allowable road gradient $\left(v_{\max }\right)$, etc.) correspond to road type\#1 "standard road" of Table 2

2. Scenario II, in which slope gradient was considered the only parameter affecting the spatial variability of construction costs. The geotechnical parameters correspond to geotechnical unit\#10 "standard subsoil" of Table 1.
Spatial variability of construction costs

The $35-\mathrm{km}^{2}$ project area included the lake "Wägital" at the eastern boundary and a watershed at the western boundary. For each of these three scenarios we calculated in each grid cell the potential road life-cycle cost for a unit length of $1 \mathrm{~m}$, assuming a straight alignment of the road parallel to the contour line. Figure 7 illustrates the spatial variability in road life-cycle costs for Scenario III, which considered both slope gradient and geotechnical soil properties. Figure 8 presents the variability of life-cycle cost per unit for the three model scenarios as cumulated frequency curves.

Scenario I assumed a route independent cost of $240 \mathrm{CHF} / \mathrm{m}$. Therefore the variability is zero, resulting in a vertical straight line of cumulated frequency curve.
Table 4 Quantiles of cost estimation after scenarios I, II, III

\begin{tabular}{|c|c|c|c|c|c|c|c|c|}
\hline & \multicolumn{2}{|c|}{$\begin{array}{l}10 \% \text {-quantile } \\
\left(Q_{0.1}\right)\end{array}$} & \multicolumn{2}{|c|}{ Median $(50 \%)$} & \multicolumn{2}{|c|}{$\begin{array}{l}90 \% \text {-quantile } \\
\left(Q_{0.9}\right)\end{array}$} & \multicolumn{2}{|c|}{$\begin{array}{l}\text { Difference } \\
\left(Q_{0.9}-Q_{0.1}\right)\end{array}$} \\
\hline & $\mathrm{CHF}$ & EUR & $\mathrm{CHF}$ & EUR & $\mathrm{CHF}$ & EUR & $\mathrm{CHF}$ & EUR \\
\hline Scenario I & 240.0 & 155.8 & 240.0 & 155.8 & 240.0 & 155.8 & 0.0 & 0.0 \\
\hline Scenario II & 160.1 & 104.0 & 179.0 & 116.2 & 234.2 & 152.1 & 74.1 & 48.1 \\
\hline Scenario III & 139.5 & 90.6 & 238.0 & 154.5 & 441.6 & 286.8 & 302.1 & 196.2 \\
\hline
\end{tabular}


Fig. 9 Model-designed road network for Scenarios I, II, and III, based on cost-estimating strategies defined in evaluation layout. Background: hill shade of relief, streams, and lake

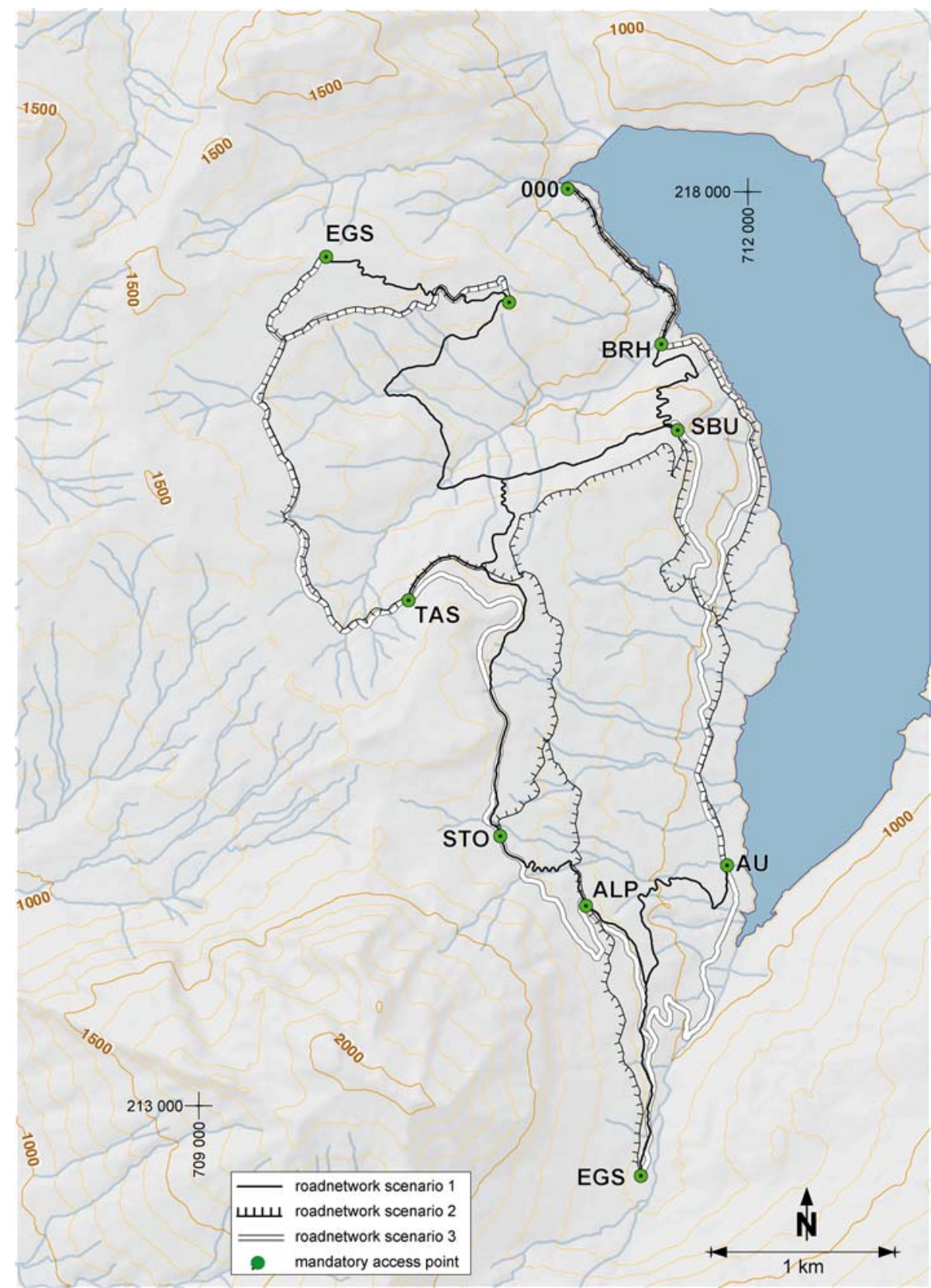

Table 5 Key values calculated for road network, based on three different cost-estimation scenarios

\begin{tabular}{lllll}
\hline Criterion & Unit & Scenario I & Scenario II & Scenario III \\
\hline Network length & $\mathrm{m}$ & 17,406 & 18,176 & 19,001 \\
Embankment and retaining structures & $1,000 \mathrm{CHF}$ & 3,098 & 1,972 & 1,847 \\
Pavement structure & $1,000 \mathrm{CHF}$ & 3,337 & 3,062 & 2,871 \\
Drainage and stream-crossing structures & $1,000 \mathrm{CHF}$ & 207 & 298 & 167 \\
Total construction cost & $1,000 \mathrm{CHF}$ & 6,642 & 5,332 & 4,885 \\
Avg. construction cost & $\mathrm{CHF} / \mathrm{m}$ & 382 & 293 & 257 \\
Maintenance cost/year & $1,000 \mathrm{CHF} / \mathrm{a}$ & 50.1 & 67.7 & 50.9 \\
Net present value (50 years) & $1,000 \mathrm{CHF}$ & 8,196 & 7,430 & 6,464 \\
Relative difference & & Reference & $-17 \%$ & $-21 \%$ \\
& & $+27 \%$ & $+15 \%$ & Reference \\
\hline
\end{tabular}


Scenario II, which considers terrain slope gradient as the only factor influencing construction cost resulted in a median cost of about $180 \mathrm{CHF} / \mathrm{m}$ with a range of about $75 \mathrm{CHF} / \mathrm{m}$ between the $10 \%$-quantile $\left(Q_{0.1}\right)$ and $90 \%$ quantile $\left(Q_{0.9}\right)$ (Table 4$)$. The cumulated frequency curve represents more or less the distribution of the slope gradients in the project area.

Scenario III represents a cost estimating procedure that considers terrain, slope, and different road types resulted in a cumulative frequency curve with median cost of about $240 \mathrm{CHF} / \mathrm{m}$ and a variability range of about $300 \mathrm{CHF} / \mathrm{m}$. The huge cost variability is a result of different subsoil that was represented by three classes: (a) stable subsoil in limestone and moraine, (b) instable subsoil in flysch formation and high landslide activity, and (c) stream crossing sites with laborious construction work.

The cumulative frequency curves of Scenario II and III asymptotically converge to the $100 \%$ line. However, values above the $98 \%$-quantile should be excluded from analysis due to model limitation for very steep terrain conditions.

Assuming that Scenario III is closest to reality and the most accurate procedure, the results depicted in Fig. 8 clearly demonstrate that conventional cost-estimation practices (which are route- and location independent) are inappropriate for difficult terrain conditions.

Influence of cost-estimating procedures on road network location

A minimum spanning tree problem was used to evaluate how various cost-estimating strategies affect the optimal layout of road networks. In this study, ten mandatory access points were linked by a minimum-cost network (Fig. 9). Access points 000, BRH, and $\mathrm{AU}$ are at lake level (about $900 \mathrm{mNN}$ ), ROW, SBU, ALP, and OBO have a intermediate elevation between $1,000 \mathrm{mNN}$ and $1,200 \mathrm{mNN}$, and EGS, TAS, and STO have a high elevation of about $1,300 \mathrm{mNN}$. We first devised a finite set of vertices that corresponded to the centers of all $10 \times 10$ $\mathrm{m}$ grid cells. Second, a set of road links was defined from each vertex to its adjacent vertices. Third, we formulated a set of design constraints, e.g., minimum curve radius, maximum road gradient, and turning constraints for the combination of incoming and outgoing road links (Tables 1,2). We then calculated the first- and second-order Steiner points (Prömel and Steger 2002). Finally, we identified the minimum cost spanning tree by combining Dijkstra's (1959) shortest path (SP) and Prim's (1957) minimum spanning tree (MST) algorithms (see also Stückelberger et al. 2004).

Figure 9 presents the evaluation results for the three scenarios. A visual assessment of the map demonstrates that the three strategies greatly affected the spatial layout of the road network. Scenario I has two connections from lake level to high level (BRH-SBU-ROW-EGS and
AU-ALP-STO). Because the costs are route independent, the model tried to keep the road network at minimal length. Both effects resulted in a lot of switchbacks and therefore high life-cycle cost. Scenarios II and III shows nearly identical road routes in 000-BRH-SBUAU and EGS-ROW-TAS. However, Scenario II connects the high level via access points AU-SBU-STO in less stable subsoil where as Scenario III made a connection via AU-OBO-ALP-STO in limestone layer, which is stable and therefore favorable.

Table 5 contains key data for the scenarios. Again, Scenario I depicted current engineering practices, which assumed route-independent costs. Optimization for this scenario resulted in the shortest road length $(17.4 \mathrm{~km})$, but the highest life-cycle cost $(+27 \%)$ compared with the minimum cost alternative. Scenario II (slope gradient only) produced a total network length of $18.2 \mathrm{~km}$. Compared to the minimum cost alternative, this scenario resulted in life-cycle costs of $15 \%$ above the minimum but $17 \%$ below the conventional practice. Finally, Scenario III, with both slope gradient and geotechnical information as major decisive parameters, was most cost-effective, with a minimum road network tree and life-cycle costs $21 \%$ lower than those incurred by standard, current practices.

\section{Conclusions}

We have developed a model for estimating forest road construction costs. This system considers location-specific terrain and subsoil parameters, and can be used to evaluate how various cost-estimating strategies affect the optimal layout of road networks. Our model consists of four element groups-embankment, retaining, pavement, and drainage structures - their dimensions and quantities being defined in terms of topographic, subsoil, and cross-sectional parameters. A spatial database that comprises a digital elevation model $(10 \times 10-\mathrm{m}$ resolution) and specifications for geotechnical formations is a prerequisite if one is to derive location-specific terrain parameters. Our validation and evaluation of this model demonstrated that: (1) under difficult terrain conditions, construction costs can range from 140 (10\%-quantile) to 440 CHF (90\%-quantile) per unit of length, thereby typically requiring a factor of about 3 between minimum and maximum costs; (2) a cost-estimating procedure that incorporates both slope gradient and geotechnical properties of the subsoil results in an optimal road network in which, compared with current engineering practices, construction costs are reduced by about $25 \%$ and life-cycle costs by about $20 \%$, all while road lengths increase about $10 \%$; and (3) a cost-estimating procedure that considers only slope gradient can still produce an optimal road network with $20 \%$ lower construction costs and $17 \%$ lower life-cycle costs. Therefore, based on these results, we believe that spatial variability in construction costs decisively affects the identification of an optimal road network, and that an improved strategy 
for cost estimations should become a matter of course for engineering practices.

Our approach may be used in any case for which site specific life-cycle cost information is available for element groups (1) embankment, (2) supporting and retaining, (3) pavement, and (4) drainage structures. However, the model is restricted to terrain conditions with slope gradient below $150 \%$, where height of retaining structures is less than $3 \mathrm{~m}$, and where no bridges and tunnels are required. Nonetheless, our validation also revealed some uncertainty that requires further investigation. A first problem consists of stream crossings for which we implemented only the ford-case. In some sites bridges may be more appropriate. A second problem is the road location near sharp terrain edges and small channels for which a $10 \times 10-\mathrm{m}$ grid resolution is inappropriate to map these small-scale terrain features. Finally protective structures against natural hazards (rock fall, mudflow, avalanches) which result in additional cost, is a third problem to be investigated for extreme area conditions.

\section{References}

AASHTO (1993) AASHTO guide for design of pavement structures. American Association of State Highway and Transportation Officials, Washington, DC

Anderson AE, Nelson J (2004) Projecting vectorbased road networks with a shortest path algorithm. Can J For Res 34:14441457

Aruga K, Sessions J, Akay A, Chung W (2004) Optimizing horizontal and vertical alignments of forest roads using a high resolution DEM. In: Clark M (ed) A joint conference of IUFRO 3.06 Forest operations under mountainous conditions and the 12th international mountain logging conference. FERIC, University of British Columbia, Vancouver, CD-ROM

Burlet E (1980) Dimensionierung und Verstärkung von Strassen mit geringem Verkehr und flexiblem Oberbau [Dimensioning and reinforcement of low volume road with flexible pavement structure]. PhD Thesis, Section of Forest Engineering, Swiss Institute of Technology, Zurich

CCE (1991) Elementarkostengliederung EKG - Kostengliederung nach Elementen für Hoch- und Tiefbau mit Projektkostengliederung [Cost classification by elements CCE - cost classification by elements for building and civil engineering]. Number 506502 in SN. Swiss Research Center for Rationalization and Civil Engineering, Zurich

Chung W, Sessions J (2001) Network 2001-transportation planning under multiple objectives. In: Schiess P, Krogstad F (eds) The international mountain logging and 11th Pacific northwest skyline symposium 2001. College of Forest Resources, University of Washington, Seattle, CD-ROM

Coulomb CA (1776) Essai sur une application des règles de maximis \& minims à quelques problèmes de statique, relatifs à l'architecture. [An essay on an application of rules of maximum and minimum to some statical problems, relevant to architecture] Mémoires de Mathématique \& de Physique, présentés à l'Académie Royale de Sciences par divers Savants 7 (1773):343382

Dijkstra EW (1959) A note on two problems in connexion with graphs. Num Math 1:269-271

Durston TA, Ou F-L (1983) Simplified cost-estimation method for low-volume roads. Transp Res Rec J Transp Res Bd 898:47-51

Dykstra DA (1976) Timber harvest layout by mathematical and heuristic programming. PhD Thesis, Department of Forest Engineering, Oregon State University

Epstein R, Weintraub A, Sessions J, Sessions B, Sapunar P, Nieto E, Bustamante F, Musante H (2001) PLANEX: A system to identify landing locations and access. In: Schiess P, Krogstad F (eds) The international mountain logging and 11th Pacific northwest skyline symposium 2001. College of Forest Resources, University of Washington, Seattle, pp 190-193

Heinimann HR (1998) A computer model to differentiate skidder and cable-yarder based road network concepts on steep slopes. J For Res (Japan) 3:1-9

Heinimann HR, Stückelberger J, Chung W (2003) Improving automatic grid cell based road route location procedures. In: Stampfer K (ed) Proceedings Austro 2003, CD-ROM

Inaba S, Heinimann HR, Shiba M (2001) A model to estimate rock excavation volume of forest roads in steep terrain conditions. In: Proceedings of the 112th meeting of the Japanese Forestry Society

Kirby M (1973) An example of optimal planning of forest roads and projects. In: Planning and decision making as applied to forest harvesting. Forest Research Laboratory, School of Forestry, Oregon State University, Corvallis, pp 75-83

Mandt CI (1973) Network analyses in transportation planning. In: Planning and decision making as applied to forest harvesting. Forest Research Laboratory, School of Forestry, Oregon State University, Corvallis, pp 95-101

Markow MJ, Aw WB (1983) Estimating road construction cost for sector planning in developing countries. Transp Res Rec J Transp Res Bd 898:52-61

Park CS, Sharp-Bette GP (1990) Advanced engineering economics. Wiley, New York

Prim RC (1957) Shortest connection networks and some generalizations. Bell Syst Tech J 36:1389-1401

Prömel H-J, Steger A (2002) The Steiner tree problem: a tour through graphs, algorithms and complexity. Advanced Lectures in Mathematics. Vieweg, Wiesbaden (D)

Stückelberger JA, Heinimann HR, Chung W (2004) Improving the effectiveness of automatic grid cell based road route location procedures. In: Clark M (ed) A joint conference of IUFRO 3.06 forest operations under mountainous conditions and the 12th international mountain logging conference. FERIC, University of British Columbia, Vancouver, CD-ROM

Terzaghi K (1944) Theoretical soil mechanics, 2nd edn. Wiley, New York

Twito RH, Reutebuch E, Stephen E (1987) Preliminary logging analysis system (PLANS): Overview. Technical Report, PNWBTR-199. USDA Forest Service, Pacific Northwest Research Station, Portland

Westney RE (1997) The engineer's cost handbook. Marcel Dekker eBooks, New York 